\title{
The Myokine Irisin Promotes Osteogenic Differentiation of Dental Bud-Derived MSCs
}

\author{
Francesca Posa ${ }^{1} \mathbb{D}$, Graziana Colaianni ${ }^{2}$, Michele Di Cosola ${ }^{1}$, Manuela Dicarlo ${ }^{2}$, Francesco Gaccione ${ }^{2}$, \\ Silvia Colucci ${ }^{3}$, Maria Grano ${ }^{2,+}$ (D) and Giorgio Mori ${ }^{1, *,+}$ (D)
}

1 Department of Clinical and Experimental Medicine, University of Foggia, Viale Pinto 1, 71122 Foggia, Italy; francesca.posa@unifg.it (F.P.); dr.dicosola@gmail.com (M.D.C.)

2 Department of Emergency and Organ Transplantation, University of Bari, 70124 Bari, Italy; graziana.colaianni@uniba.it (G.C.); manuela.dicarlo25@gmail.com (M.D.); fra.gaccione@gmail.com (F.G.); maria.grano@uniba.it (M.G.)

3 Department of Basic Medical Sciences, Neuroscience and Sense Organs, Section of Human Anatomy and Histology, University of Bari, 70124 Bari, Italy; silviaconcetta.colucci@uniba.it

* Correspondence: giorgio.mori@unifg.it

+ These authors contributed equally to this work.

Citation: Posa, F.; Colaianni, G.; Di Cosola, M.; Dicarlo, M.; Gaccione, F.; Colucci, S.; Grano, M.; Mori, G. The Myokine Irisin Promotes Osteogenic Differentiation of Dental Bud-Derived MSCs. Biology 2021, 10, 295. https:/ / doi.org/10.3390/biology10040295

Academic Editor: Bruce Young

Received: 19 February 2021

Accepted: 30 March 2021

Published: 3 April 2021

Publisher's Note: MDPI stays neutral with regard to jurisdictional claims in published maps and institutional affiliations.

Copyright: (c) 2021 by the authors. Licensee MDPI, Basel, Switzerland. This article is an open access article distributed under the terms and conditions of the Creative Commons Attribution (CC BY) license (https:// creativecommons.org/licenses/by/ $4.0 /)$.
Simple Summary: Irisin is a recently discovered protein, mainly produced in the muscle tissue, whose action is proving effective in many other tissues. The crosstalk between muscle and bone has been long since demonstrated, and physical activity has shown to have an impressive positive effect in both tissues. Irisin production increases with exercising and drops with sedentariness and aging, indicating that the molecule is involved in sarcopenia and in bone mass reduction. Although skeleton is target of irisin, its mechanism of action on bone cells has not yet been completely elucidated. The aim of this work is to analyze the effect of irisin on osteoblast differentiation; to this purpose, we used a stem cell model reproducing the osteoblastogenesis and the bone-forming processes. We performed an in vitro study exploring the main osteoblast markers in the presence of irisin. We found that irisin has an impressive effect on the most peculiar osteoblast feature: the bone mineral matrix secretion process. Moreover, irisin demonstrated an inductive effect on osteoblast osteocalcin production. Both results suggest a stimulating effect of irisin in bone formation. The association we observed between irisin addition and osteoblast osteocalcin production should be further investigated.

Abstract: The myokine irisin, well known for its anabolic effect on bone tissue, has been demonstrated to positively act on osteoblastic differentiation processes in vitro. Mesenchymal stem cells (MSCs) have captured great attention in precision medicine and translational research for several decades due to their differentiation capacity, potent immunomodulatory properties, and their ability to be easily cultured and manipulated. Dental bud stem cells (DBSCs) are MSCs, isolated from dental tissues, that can effectively undergo osteoblastic differentiation. In this study, we analyzed, for the first time, the effects of irisin on DBSC osteogenic differentiation in vitro. Our results indicated that DBSCs were responsive to irisin, showed an enhanced expression of osteocalcin (OCN), a late marker of osteoblast differentiation, and displayed a greater mineral matrix deposition. These findings lead to deepening the mechanism of action of this promising molecule, as part of osteoblastogenesis process. Considering the in vivo studies of the effects of irisin on skeleton, irisin could improve bone tissue metabolism in MSC regenerative procedures.

Keywords: bone; irisin; osteocalcin; mesenchymal stem cells (MSCs); precision medicine; dental stem cells; osteoblastogenesis; translational research

\section{Introduction}

Mesenchymal stem cells (MSCs) are extensively used as a therapeutic resource in modern medicine; they are self-renewable and can differentiate into all cell lineages that form 
mesenchymal and connective tissues. MSCs can be applied in the treatment of numerous diseases, either alone or integrated with scaffolds; their efficacy has been reported in the therapy of wounds [1], bone and cartilage dehiscence [2], graft-versus-host disease [3], as well as cardiovascular [4] and neural disorders [5].

Stem cell populations present in the bone marrow are the most studied MSCs; other possible alternatives reside in many different parts of the organism, such as adipose tissue, as well as brain, liver, and dental tissues [6].

Dental tissues such as dental pulp, apical papilla, and periodontal ligament are recognized as a good source of MSCs; in particular, dental pulp is a connective tissue with an abundance of stem cells in the perivascular niche, which is similar to the embryonal mesenchyme $[7,8]$.

It has been demonstrated that dental pulp stem cells (DPSCs) express most of the osteogenic markers, thus they can be considered very similar to osteoblast precursors $[9,10]$.

The dental bud (DB) is the undifferentiated stage of the tooth, and as such it is rich in undifferentiated stem cells. The dental papilla, which we find in the mesenchymal part of the DB, contains a very large number of MSCs, more than the dental pulp; these cells express the characteristic mesenchymal stem markers and demonstrate an impressive osteoblastic phenotype [11].

The osteogenic features of dental bud stem cells (DBSCs) can be positively influenced by several molecules, such as vitamins, natural compounds, or drugs [12-16].

The recently identified myokine irisin has been demonstrated to induce periodontal ligament cell (PDLC) growth, migration, and osteogenic differentiation [17] and also to promote the odontogenic differentiation of DPSCs [18].

Irisin has been previously described as a circulating myokine secreted from skeletal muscle in response to exercise. Later, the skeleton was identified as the principal target of irisin that is involved in both osteoblast proliferation [19] and differentiation [20,21].

Thus, irisin plays an important role in bone remodeling; moreover, in vivo studies on mice models have shown that low doses of irisin, administered intermittently, improve mineral density and some important mechanical bone features [22-24].

DBSCs, when properly cultured, undergo osteogenic differentiation, expressing the typical markers and forming mineralized matrix; therefore, they can be considered an excellent osteoblastogenesis model. In this study, we investigate the role of irisin on our model of osteoblastogenesis.

\section{Materials and Methods}

\subsection{Dental Bud Stem Cells (DBSCs) Cultures}

Dental buds (DBs) were isolated from the third molar of ten pediatric patients (8-12 years) undergoing dental extractions for orthodontic reasons, after receiving their parents' informed consent.

The inner part of the DB, the dental papilla, was cut into small pieces and enzymatically digested, using a digesting medium containing $3 \mathrm{mg} / \mathrm{mL}$ Type I collagenase and 4 $\mathrm{mg} / \mathrm{mL}$ dispase, until a suspension consisting of single cells was obtained [25]. DBSCs were seeded and expanded in vitro as previously described $[7,9,11,26,27]$.

In the experiments aimed to examine the effect of irisin on DBCSs, cells were seeded with a density of $15 \times 10^{3} / \mathrm{cm}^{2}$ in Dulbecco's modified Eagle's medium (D-MEM) (Thermo Fisher Scientific, Waltham, MA, USA) supplemented with $5 \%$ heat-inactivated fetal bovine serum (FBS), 1\% penicillin/streptomycin (Thermo Fisher Scientific, Waltham, MA, USA), in 6-well plates. After 2 days of culture, DBSCs were starved for at least $3 \mathrm{~h}$ and subsequently stimulated with $100 \mathrm{ng} / \mathrm{mL}$ of irisin for the different time points.

Then, we induced DBSCs osteogenic differentiation in vitro: cells were seeded with a density of $5 \times 10^{3} / \mathrm{cm}^{2}$ in 24-well plates (for staining) and 6-well plates (for Western blot), cultured in the osteogenic medium consisting of D-MEM supplemented with $2 \%$ FBS, $10^{-8} \mathrm{M}$ dexamethasone, and $50 \mu \mathrm{g} / \mathrm{mL}$ ascorbic acid. For the evaluation of mineralized matrix nodule formation, $10 \mathrm{mM} \beta$-glycerophosphate (Sigma Aldrich, Milan, Italy) was 
also added to the osteogenic medium. Cells cultured in these conditions were treated or not (Ctr) with irisin, added to the culture medium at every change (every 3 days).

\subsection{Irisin Treatment}

Irisin (Adipogen, Liestal, Switzerland), was reconstituted at $100 \mu \mathrm{g} / \mathrm{mL}$ in Milli-Q water and stored at $-20{ }^{\circ} \mathrm{C}$ before use. We treated one part of the cells with a concentration of $100 \mathrm{ng} / \mathrm{mL}$ irisin (treatment group), added to the medium. The part of the cells that was not treated with irisin served as the control group (Ctr).

\subsection{Western Blot}

Revelation of pERK at protein levels was performed using SDS-PAGE gel electrophoresis and Western blot analysis. After DBSC starvation in serum-free D-MEM for at least $3 \mathrm{~h}$, irisin was added or not (Ctr) to the medium. Undifferentiated DBSCs, after 2 days of culture, were stimulated with irisin for $0,5,7,10$, or 20 min; differentiated DBSCs, after 10 days of osteogenic differentiation, were treated with irisin for 5 or $10 \mathrm{~min}$. At the different time points, cells were lysed as previously described [11,14]. Once the total protein concentration was determined, by using a protein assay (Bio-Rad Laboratories, Hercules, CA, USA), the same amounts of protein for each sample were separated via SDS-PAGE and transferred to nitrocellulose membranes (Invitrogen, Carlsbad, CA, USA). Blots were then probed with primary and secondary antibodies. Anti-pERK and anti-total ERK antibodies were purchased from Santa Cruz Biotechnology (Dallas, TX, USA). The visualization of the immune complexes was carried out using the Odyssey Infrared Imaging System of LI-COR (LI-COR Biotechnology, Lincoln, NE, USA).

\subsection{Real-Time PCR}

DBSCs were cultured in 6-well plates and the total RNA was extracted utilizing spin columns (RNeasy, Qiagen, Hilden, Germany) after 3 or $8 \mathrm{~h}$ of stimulation with irisin. Then, $2 \mu \mathrm{g}$ of RNA was reverse transcribed (RT) by using SuperScript First-Strand Synthesis System kit (BioRad iScript Reverse Transcription Supermix). Afterwards, 20 ng of the synthesized cDNA were used for the quantitative PCR. Real-time PCR analysis was carried out using the SsoFast EvaGreen Supermix (Bio-Rad Laboratories, Hercules, CA, USA) on a CFX96 Real-Time System (Bio-Rad Laboratories, Hercules, CA, USA) following the manufacturer's protocol. Gene expression was calculated using the mean cycle threshold value $(\mathrm{Ct})$ from triplicate samples, normalizing the results to the average of $\beta$-actin, GAPDH, and $\beta_{2}$ microglobulin (B2M) levels for each reaction.

The following primer pairs were used for the Real Time-PCR (RT-PCR) amplification (Table 1).

Table 1. List of primer sequences used for RT-PCR.

\begin{tabular}{ccc}
\hline Gene & Sense $\mathbf{( 5}^{\prime}-\mathbf{3}^{\prime} \mathbf{)}$ & Antisense $\mathbf{( 5}^{\prime}-\mathbf{3}^{\prime} \mathbf{)}$ \\
\hline RANK-L & ACAGCACATCAGAGCAGAG & AGGACAGACTCACTTTATGGG \\
\hline OPG & CAAAGGCAGGCGATACTTCC & ATGGAGATGTCCAGAAACACGA \\
\hline OCN & CTCACACTCCTCGCCCTATTG & GCTTGGACACAAAGGCTGCAC \\
\hline Coll I (COL1A1) & TGAAGGGACACAGAGGTTTCAG & GTAGCACCATCATTTCCACGA \\
\hline RUNX-2 & CGCCTCACAAACAACCACAG & ACTGCTTGCAGCCTTAAATGAC \\
\hline BSP & CAATCTGTGCCACTCACTGC & TTTGGTGATTGCTTCCTCTGG \\
\hline$\beta$-Actin (ACTB) & AATCGTGCGTGACATTAAG & GAAGGAAGGCTGGAAGAG \\
\hline$\beta 2$ Microglobulin $(\mathrm{B} 2 \mathrm{M})$ & ATGAGTATGCCTGCCGTGTGA & GGCATCTTCAAACCTCCATG \\
\hline GAPDH & GGAGTCAACGGATTTGGT & GTGATGGGATTTCCATTGAT \\
\hline
\end{tabular}

\subsection{Alkaline Phosphatase (ALP)}

The expression of ALP, the osteoblastic differentiation marker, was determined with the Leukocyte Alkaline Phosphatase kit (Sigma Aldrich, Milan, Italy) after 7 days of DBSC osteogenic differentiation. 
Briefly, once the culture medium was removed, cells were fixed at room temperature for $5 \mathrm{~min}$, following the manufacturer's protocol. Then the cells were rinsed with deionized water and stained with ALP solution (FRV-Alkaline Solution, Naphthol AS-BI Alkaline Solution, and Sodium Nitrite Solution) for $15 \mathrm{~min}$ in the dark. At the end of the incubation time, the wells were washed again and left to dry in the air, then the cells were examined on a microscope. ALP-positive cells show a purple staining.

\subsection{Alizarin Red Staining (ARS)}

In order to test the possible involvement of irisin in inducing the production of calcium-rich deposits in vitro, ARS was carried out on DBSCs differentiated in osteogenic medium for 21 days. Once the culture medium was removed cells were rinsed with PBS and fixed in $10 \%$ formalin at room temperature for $10 \mathrm{~min}$. Then, cells were washed with deionized water and stained with a $\%$ ARS solution (Alizarin Red powder was purchased from Sigma Aldrich, Milan, Italy) for $10 \mathrm{~min}$ at room temperature. The ARS solution was discarded at the end of the incubation time, and cells were rinsed twice with deionized water and then air dried.

\subsection{Statistical Analysis}

Data are representative of three/five independent experiments. Boxplots with median and interquartile ranges show data in figures with three values per group. Box-and-whisker plots with median and interquartile ranges, from max to min, show data in figures with four or five values per group. All data points are shown. Statistical calculations were performed using GraphPad Prism version 8.0.2 for MacOS (GraphPad Software, La Jolla, CA, USA, www.graphpad.com). The results were considered statistically significant for $p<0.05$. ImageJ software (Research Services Branch, Image Analysis Software Version 1.53a, NIH, Bethesda, MD, USA) was used to process images.

\section{Results}

\subsection{Extracellular Signal-Regulated Kinase (ERK) Phosphorylation in DBSCs Treated with Irisin}

In order to clarify whether DBSCs were responsive to the treatment with the myokine or not, we performed experiments on the signaling pathways, focusing on ERK phosphorylation.

DBSC s were seeded in D-MEM supplemented with 5\% FBS, cultured for 2 days, starved for at least $3 \mathrm{~h}$, and then stimulated with irisin for the different time points. Whole cell lysates were collected and assessed by Western blot. As shown in Figure 1, pERK expression was transiently upregulated after irisin stimulation. ERK phosphorylation was significantly upregulated after 5 and $7 \mathrm{~min}$ of irisin administration, compared to the time zero (T0), and then its level decreased, becoming comparable to the T0. These results demonstrated that DBSCs are responsive to irisin treatment by increasing pERK.

In parallel, DBSCs were cultured in the osteogenic medium and, after 10 days of differentiation, were treated with irisin for 3 or $5 \mathrm{~min}$. Interestingly, the cells appeared to be still responsive to irisin treatment and even more sensitive than the undifferentiated ones, showing a peak in the phosphorylation of ERK at 3 min (Figure 2), which already decreased after 5 min stimulation. 


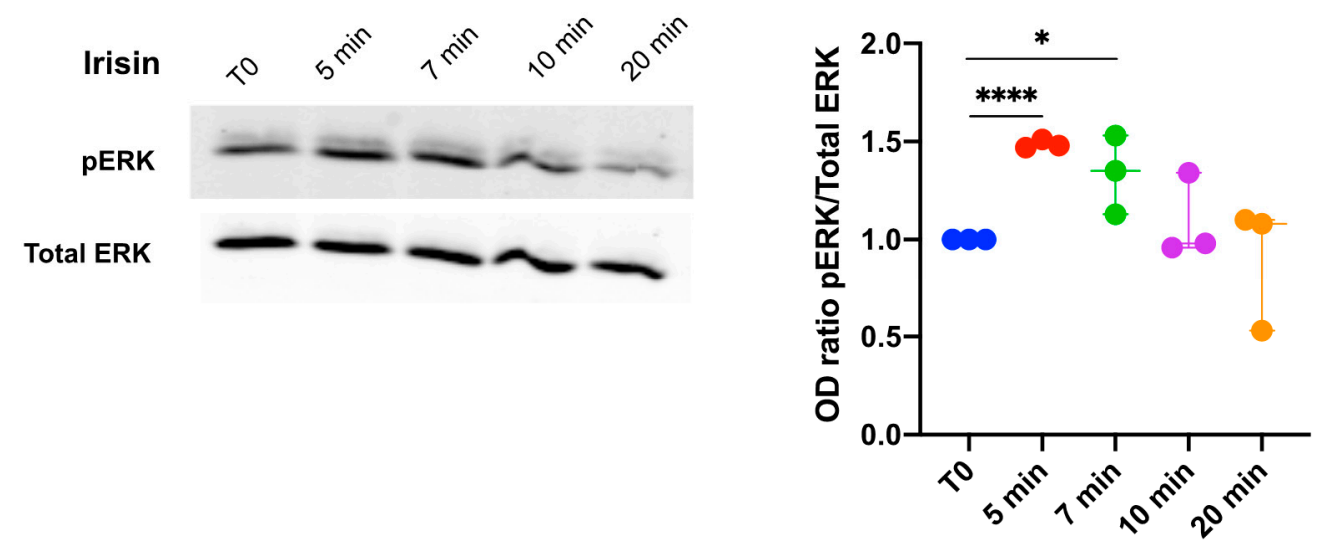

Figure 1. Effects of irisin on extracellular signal-regulated kinase (ERK) phosphorylation (pERK) in DBSCs cultures. Dental bud stem cells (DBSCs) were stimulated with irisin for the indicated time points. Phosphorylated and total ERK expression levels in cell lysates were examined by Western blot and measured with corresponding densitometry band quantification. Densitometric analysis is expressed as the relative optical density (OD) of the bands normalized to total ERK. The graph shows that the treatment significantly, but transiently, increased the protein expression level of pERK after 5 and 7 min of stimulation. The graph represents data as a boxplot with median and interquartile ranges of $n=3$ independent experiments. ${ }^{*} p<0.05,{ }^{* * * *} p<0.0001$. Statistics: unpaired Student's $t$-test.
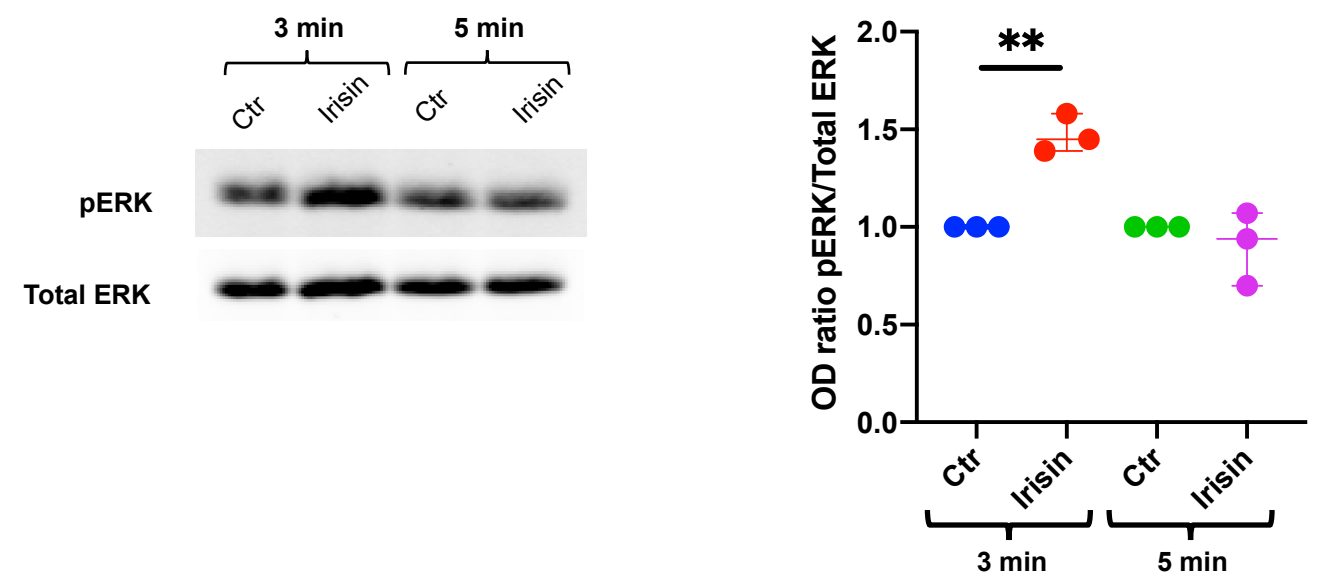

Figure 2. Effects of irisin on pERK in differentiated DBSCs. DBSCs, differentiated in osteogenic medium for 10 days, were stimulated with irisin for 3 or 5 min. pERK and total ERK expression levels in cell lysates were examined by Western blot and measured with corresponding densitometric quantification. Densitometric analysis is expressed as the relative optical density (OD) of the bands normalized to total ERK. The graph shows that the treatment significantly increased the protein expression level of pERK after 3 min of stimulation. The graph represents data as a boxplot with median and interquartile ranges of $n=3$ independent experiments. ${ }^{* *} p<0.01$. Statistics: unpaired Student's $t$-test.

\subsection{Irisin Stimulation Increases Osteocalcin (OCN) Expression in DBSCs}

Once the responsiveness of our cell model to irisin was confirmed, in order to find out if this myokine could affect the DBSC acquisition of osteoblastic features, we assessed the mRNA expression level of the main osteoblastic markers performing RT-PCR. DBSCs cultured in the appropriate conditions were stimulated or not (Ctr) with irisin for 3 or $8 \mathrm{~h}$ and, following this treatment, we identified the most exciting effect of irisin in OCN expression. Figure 3 shows that OCN mRNA levels, although comparable between Ctr and treatment at $3 \mathrm{~h}$, greatly increased in the cells treated with irisin after $8 \mathrm{~h}$ of stimulation. This enhancement in OCN expression also turned out to be statistically significant. Interestingly, for all the other osteoblastic markers analyzed (i.e., RANK-L, osteoprotegerin (OPG), collagen I, RUNX-2, and bone sialoprotein (BSP)), we did not reveal any significant change 
in mRNA expression level at 3 or $8 \mathrm{~h}$ of irisin treatment. Nevertheless, it should be noted that the expression of some of these markers appeared to follow a growing trend in the treatment compared to the control (Figure 3, RANK-L, RUNX-2, and BSP graphs), particularly after $8 \mathrm{~h}$ of stimulation.
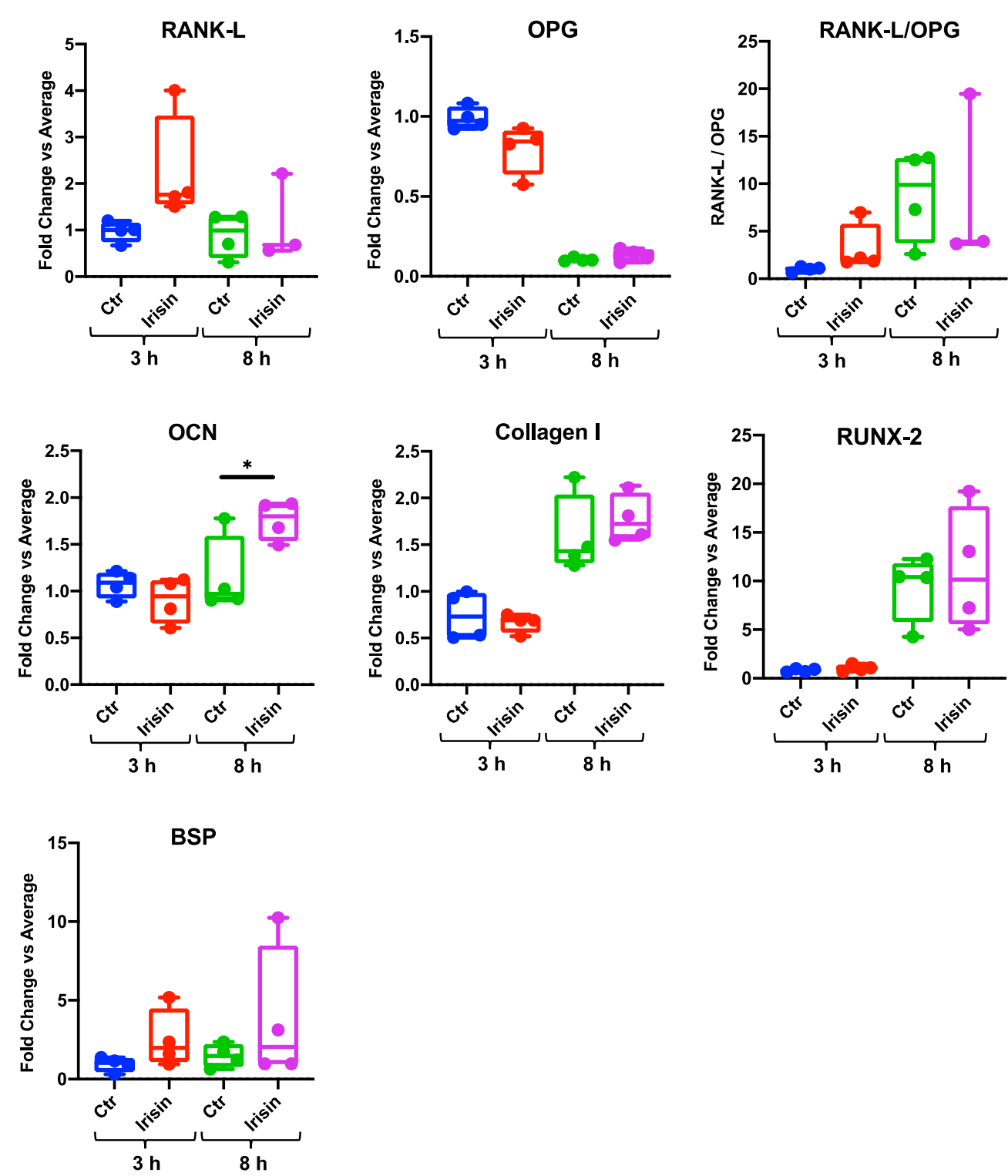

Figure 3. Effects of irisin on the expression of osteoblast markers at mRNA level. mRNA expression levels of osteoblast marker genes (RANK-L, osteoprotegerin (OPG), osteocalcin (OCN), collagen I, RUNX-2, and bone sialoprotein (BSP)) were assayed (qPCR) after 3 and $8 \mathrm{~h}$ of stimulation with irisin. The graph shows that the treatment significantly enhanced the expression of the osteoblast marker OCN. Expression was normalized to the average of $\beta$-actin, $\beta_{2}$ microglobulin (B2M), and GAPDH levels for each reaction. Graphs represent data as box-and-whisker plots with median and interquartile ranges, from max to min, of four independent experiments performed in triplicate. ${ }^{*} p<0.05$ compared to Ctr. Student's $t$-test was used for single comparisons.

\subsection{ALP Positivity and Calcium-Rich Deposit Formation in DBSCs}

In order to examine the ability of irisin to induce DBSC differentiation in osteoblasts, cells were cultured in osteogenic medium and stimulated with $100 \mathrm{ng} / \mathrm{mL}$ of irisin, which was added to the medium at every renewal (every 3 days). DBSC cultures were stopped at 7 and 21 days of continuous irisin treatment in differentiating conditions. 
After 7 days of continuous stimulation, we evaluated DBSC alkaline phosphatase (ALP) expression by using the ALP staining. We found that there were only slight differences between $\mathrm{Ctr}$ and irisin treatment in the expression of this typical osteoblastic marker (Figure 4a), which were not significant (Figure 4b).

(a)
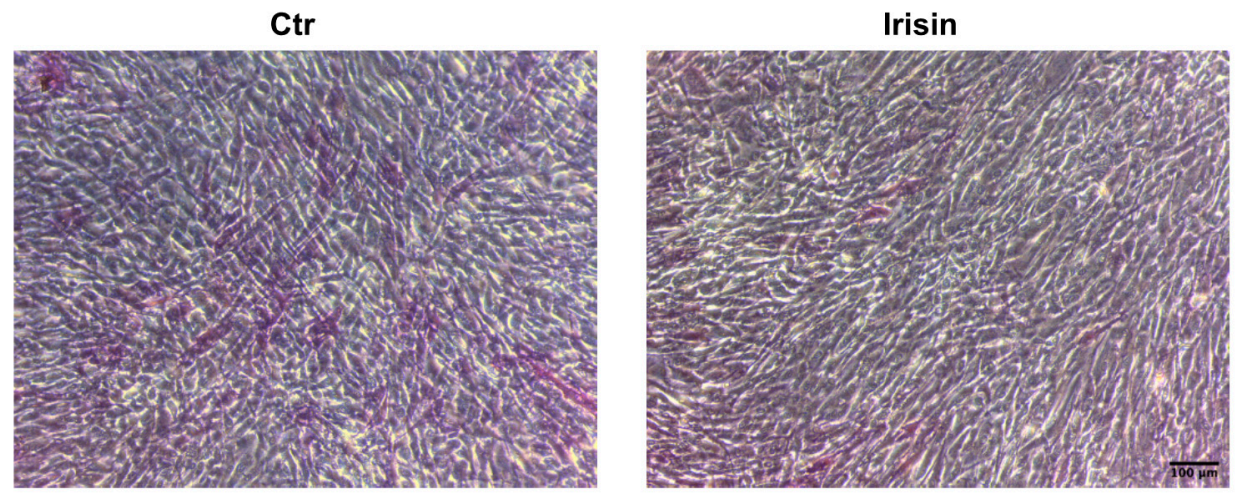

(b)

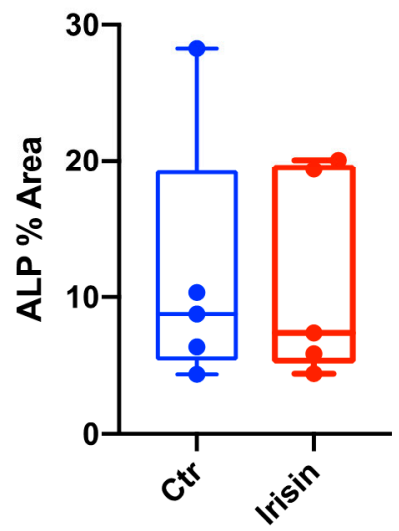

Figure 4. Alkaline phosphatase (ALP) expression in DBSCs. (a) ALP expression assayed by ALP cytochemical assay (purple staining) in DBSCs cultured in osteogenic conditions and treated with irisin or not (Ctr) for 7 days. Representative phase contrast pictures were chosen for the figure. Scale bar: $100 \mu \mathrm{m}$. (b) The graph shows the quantification of ALP \% area presented as box-andwhisker plots with median and interquartile ranges, from max to min, and is representative for five independent experiments performed in quadruplicates.

Furthermore, long-term cultures proved the ability of DBSCs, when suitably differentiated in an osteogenic sense, to form calcium-rich deposits in vitro. This process, which characterizes the final step of matrix production by osteoblasts, was assessed with ARS quantification after 21 days of osteogenic differentiation. Interestingly, DBSC deposition of mineral matrix nodules was greater when cells were treated with irisin, compared to the control (Figure $5 \mathrm{a}, \mathrm{b}$ ). These observations were confirmed by the quantitative analysis of the percentage area covered by the red staining (Figure $5 c$ ), which was significantly higher in the treatment with irisin when compared to the Ctr. 
(a)

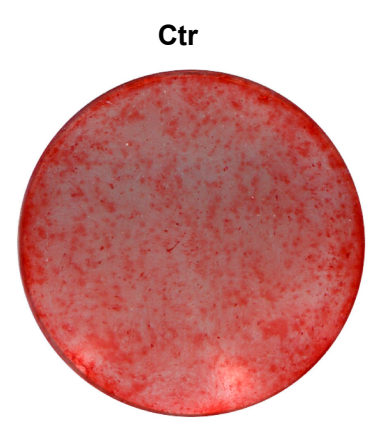

(b)

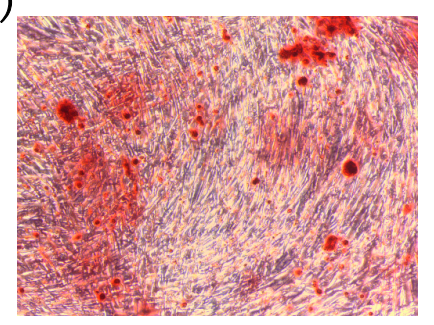

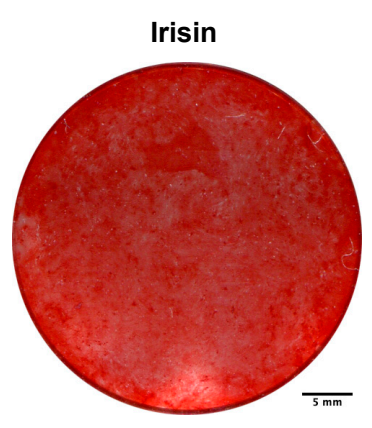

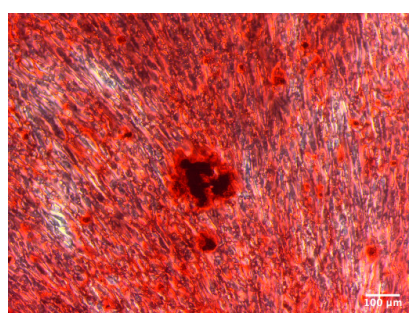

(c)

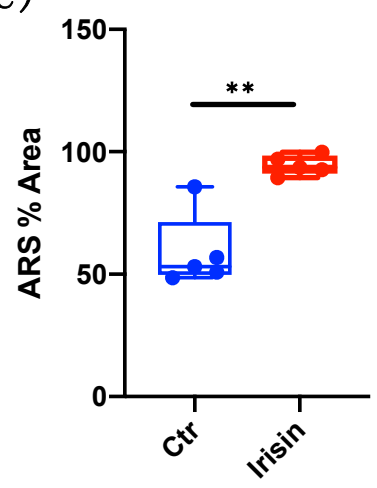

Figure 5. Mineralized nodules formation following irisin stimulation and alizarin red staining (ARS) quantification. (a) Mineral matrix deposition, assessed by ARS (red staining), in DBSCs cultured in osteogenic conditions and treated with irisin or not (Ctr) for 21 days. The figure shows the wells of a representative experiment. Scale bar: $5 \mathrm{~mm}$. (b) Phase contrast pictures displaying the formation of calcified nodules. Scale bar: $100 \mu \mathrm{m}$. (c) The graph shows the quantification of ARS \% area presented as box-and-whisker plots with median and interquartile ranges, from max to min, and is representative for five independent experiments performed in quadruplicates. ${ }^{* *} p<0.01$. Statistics: unpaired Student's $t$-test.

\section{Discussion}

Both myokine irisin and MSCs have elicited worldwide interest for their extensive potential to treat a large array of translational clinical indications, allowing ample discussions and debates regarding their possible applications in the forthcoming era of precision medicine.

To the best knowledge of the authors, this is the first time that the influence of irisin, a powerful myokine for bone tissue physiology, has been investigated on MSCs from dental bud.

We previously reported that DBSCs constitute a perfect model of osteoblastogenesis [11], thus the mesenchymal part of the bud is a great source of MSCs that can acquire osteogenic features. In this study, we analyzed the effects of irisin on our cell model, examining the expression of the main markers of osteoblast differentiation and focusing on DBSC activity.

All the anabolic effects of irisin on bone have being explored only in recent years, and its functional receptor is still a critical point of study. It has been recently shown that irisin acts on osteocytes by binding to an $\alpha \mathrm{v}$ integrin receptor and promoting osteocytes survival [28], but there is still a number of unresolved questions regarding the mechanism. Among the primary signaling events that occur when an integrin receptor is activated by the binding of its ligand, there is the stimulation of the ERK cascade [29]. The phosphorylation of ERK has been already demonstrated as a key pathway in osteoblastic proliferation and differentiation induced by irisin [19].

Firstly, we demonstrated a cellular response, with the phosphorylation of ERK following irisin administration, indicating that DBSCs are responsive to irisin.

Irisin is known to directly stimulate osteoblast proliferation, differentiation, and mineralization in vitro, by increasing ERK phosphorylation [19,20]. More recently, irisin has also been demonstrated to promote matrix formation in PDLCs [17] and hDPSCs [18]. 
Our results are in line with the data from previous literature and show, for the first time, that DBSCs respond to irisin stimulation; moreover, it was observed that the cells maintained their responsiveness to the myokine even when they were cultured in osteogenic conditions, and induced to differentiate to osteoblasts. Afterwards, we also observed that the mineral matrix deposition was significantly increased in DBSCs cultured in osteogenic condition and continuously treated with irisin. The production of calcium-rich deposits is the most peculiar osteoblast feature, and MSCs or DBSCs, opportunely differentiated, can effectively secrete a mineralized matrix in vitro $[11,30]$.

On the contrary, irisin did not affect ALP activity in DBSCs. Although this observation is not in accordance with the demonstrated effect of irisin on hDPSC ALP activity [18], it should be underlined that Son et al. made use of a much higher concentration of the molecule ( $20 \mu \mathrm{M}$ compared to $8.3 \mathrm{nM})$ normally used in such in vitro studies, and therefore is of little relevance in physiological terms [31].

Successively, collagen I, RUNX-2, BSP, OPG, and RANK-L expression were studied. Although irisin appeared to induce the expression of some of these osteogenic markers, no significant variation was found.

Remarkably, a significant myokine effect was detected on OCN expression level in DBSCs. OCN is a non-collagenic glycoprotein, present in bone matrix and circulating in blood, which is involved in osteoblast mineralization process and, in the undercarboxylated form, also in many other organism pathways [32].

Osteoblasts secrete OCN in bone matrix, where it binds to the calcium ions in hydroxyapatite, which is its mineral component. The role of $\mathrm{OCN}$ in the mineralization process has been extensively discussed in bone research, with conflicting results indicating both an inhibitory and stimulating effect [33-36].

Moreover, a previous study showed an existing positive correlation between serum levels of irisin and OCN in a population of healthy children [37]. Interestingly, in a population of older adult subjects, OCN mRNA levels measured in bone biopsies were positively associated with the mRNA expression for the irisin precursor, FNDC5, in skeletal muscle biopsies [38]. These results, obtained in humans, agreed with in vitro data showing that long-term treatment with recombinant irisin raised OCN mRNA expression in primary mouse and rat osteoblasts $[19,22]$.

Recent studies showed that $\mathrm{OCN}$ has a crucial role in bone matrix formation since it binds to hydroxyapatite and forms complex with osteopontin, which is an essential adhesion molecule for both osteoblasts and osteoclasts [39-41]. OCN hence acts as a bridge between calcium crystals and structural proteins, exerting its function at the organicinorganic interface of bone matrix, and might serve to inhibit crack, stretching and therefore dissipating energy in collagen fibers $[42,43]$. Consistently with this issue, fracture resistance is reduced in OCN null mice [44].

\section{Conclusions}

Thus, in conclusion, we can assert that the results of our study highlight a significant effect of irisin in increasing OCN expression in DBSCs. This outcome, together with the rise in matrix mineralization, indicates a major involvement of irisin in the osteogenic differentiation process of DBSCs. In addition, considering that our model resembles the osteoblastogenesis process, we can speculate that irisin administration could contribute to bone matrix deposition by the stimulation of OCN expression. Further in vivo studies will need to be performed in order to confirm this hypothesis.

Author Contributions: Conceptualization: G.M., F.P., G.C., and M.G.; formal analysis: F.P., G.C., M.D., and F.G.; investigation: F.P.; methodology: F.P.; resources: G.M., M.G., S.C., and M.D.C.; writing—original draft preparation: F.P., and G.M.; writing—review and editing: F.P., G.M.; visualization: F.P.; supervision: G.M.; funding acquisition: G.M. and M.G. All authors have read and agreed to the published version of the manuscript. 
Funding: This research was funded by Ministero dell'Istruzione, dell'Università e della RicercaPRIN 20098KM9RN, PI G.M. (Progetto di Ricerca d'Interesse Nazionale—Grant 2009) and was supported by the special grant from Regione Puglia for Tecnopolo Puglia per la Medicina di Precisione D.G.R. n. 2117 of 21.11 .2018$.

Institutional Review Board Statement: The experiments were performed according to the Declaration of Helsinki. The study was approved by the ethical committee, under the project BIADIDENT Rep 4159/2018, at Ospedali Riuniti of UniFg.

Informed Consent Statement: Informed consent was obtained from the parents or guardians of all the patients involved in the study.

Data Availability Statement: The raw/processed data required to reproduce these findings are available on request from the corresponding author. The data are not publicly available due to technical or ethical limitations.

Conflicts of Interest: Maria Grano, Graziana Colaianni, Silvia Colucci, and Giorgio Mori are name inventors of the European Patent No EP3081228B1, titled "Irisin for care and prevention of osteoporosis".

\section{References}

1. Rodgers, K.; Jadhav, S.S. The application of mesenchymal stem cells to treat thermal and radiation burns. Adv. Drug Deliv. Rev. 2018, 123, 75-81. [CrossRef] [PubMed]

2. Rodeo, S. Cell therapy in orthopaedics: Where are we in 2019? Bone Jt. J. 2019, 101, 361-364. [CrossRef] [PubMed]

3. Kebriaei, P.; Isola, L.; Bahceci, E.; Holland, K.; Rowley, S.; McGuirk, J.; Devetten, M.; Jansen, J.; Herzig, R.; Schuster, M. Adult human mesenchymal stem cells added to corticosteroid therapy for the treatment of acute graft-versus-host disease. Biol. Blood Marrow Transplant. 2009, 15, 804-811. [CrossRef]

4. Madonna, R.; Geng, Y.-J.; De Caterina, R. Adipose tissue-derived stem cells: Characterization and potential for cardiovascular repair. Arterioscler. Thromb. Vasc. Biol. 2009, 29, 1723-1729. [CrossRef]

5. Řehořová, M.; Vargová, I.; Forostyak, S.; Vacková, I.; Turnovcová, K.; Kupcová Skalníková, H.; Vodička, P.; Kubinová, Š.; Syková, E.; Jendelová, P. A Combination of Intrathecal and Intramuscular Application of Human Mesenchymal Stem Cells Partly Reduces the Activation of Necroptosis in the Spinal Cord of SOD1G93A Rats. Stem Cells Transl. Med. 2019, 8, 535-547. [CrossRef]

6. $\quad$ Pittenger, M.F.; Mackay, A.M.; Beck, S.C.; Jaiswal, R.K.; Douglas, R.; Mosca, J.D.; Moorman, M.A.; Simonetti, D.W.; Craig, S.; Marshak, D.R. Multilineage potential of adult human mesenchymal stem cells. Science 1999, 284, 143-147. [CrossRef] [PubMed]

7. Gronthos, S.; Mankani, M.; Brahim, J.; Robey, P.G.; Shi, S. Postnatal human dental pulp stem cells (DPSCs) in vitro and in vivo. Proc. Natl. Acad. Sci. USA 2000, 97, 13625-13630. [CrossRef]

8. Huang, G.-J.; Gronthos, S.; Shi, S. Mesenchymal stem cells derived from dental tissues vs. those from other sources: Their biology and role in regenerative medicine. J. Dent. Res. 2009, 88, 792-806. [CrossRef]

9. Mori, G.; Brunetti, G.; Oranger, A.; Carbone, C.; Ballini, A.; Muzio, L.L.; Colucci, S.; Mori, C.; Grassi, F.R.; Grano, M. Dental pulp stem cells: Osteogenic differentiation and gene expression. Ann. N. Y. Acad. Sci. 2011, 1237, 47-52. [CrossRef]

10. Mori, G.; Centonze, M.; Brunetti, G.; Ballini, A.; Oranger, A.; Mori, C.; Lo, L.M.; Tetè, S.; Ciccolella, F.; Colucci, S. Osteogenic properties of human dental pulp stem cells. J. Biol. Regul. Homeost. Agents 2010, 24, 167-175.

11. Di Benedetto, A.; Brunetti, G.; Posa, F.; Ballini, A.; Grassi, F.R.; Colaianni, G.; Colucci, S.; Rossi, E.; Cavalcanti-Adam, E.A.; Muzio, L.L. Osteogenic differentiation of mesenchymal stem cells from dental bud: Role of integrins and cadherins. Stem Cell Res. 2015, 15, 618-628. [CrossRef]

12. Di Benedetto, A.; Posa, F.; De Maria, S.; Ravagnan, G.; Ballini, A.; Porro, C.; Trotta, T.; Grano, M.; Muzio, L.L.; Mori, G. Polydatin, natural precursor of resveratrol, promotes osteogenic differentiation of mesenchymal stem cells. Int. J. Med. Sci. 2018, 15, 944. [CrossRef] [PubMed]

13. Posa, F.; Di Benedetto, A.; Cavalcanti-Adam, E.A.; Colaianni, G.; Porro, C.; Trotta, T.; Brunetti, G.; Lo Muzio, L.; Grano, M.; Mori, G. Vitamin D promotes MSC osteogenic differentiation stimulating cell adhesion and $\alpha$ V 33 expression. Stem Cells Int. 2018, 2018. [CrossRef]

14. Posa, F.; Di Benedetto, A.; Colaianni, G.; Cavalcanti-Adam, E.A.; Brunetti, G.; Porro, C.; Trotta, T.; Grano, M.; Mori, G. Vitamin D effects on osteoblastic differentiation of mesenchymal stem cells from dental tissues. Stem Cells Int. 2016, 2016. [CrossRef] [PubMed]

15. Di Benedetto, A.; Posa, F.; Marazzi, M.; Kalemaj, Z.; Grassi, R.; Lo Muzio, L.; Comite, M.D.; Cavalcanti-Adam, E.A.; Grassi, F.R.; Mori, G. Osteogenic and Chondrogenic Potential of the Supramolecular Aggregate T-LysYal ${ }^{\circledR}$. Front. Endocrinol. 2020, 11, 285. [CrossRef] [PubMed]

16. Posa, F.; Di Benedetto, A.; Ravagnan, G.; Cavalcanti-Adam, E.A.; Lo Muzio, L.; Percoco, G.; Mori, G. Bioengineering Bone Tissue with 3D Printed Scaffolds in the Presence of Oligostilbenes. Materials 2020, 13, 4471. [CrossRef]

17. Pullisaar, H.; Colaianni, G.; Lian, A.-M.; Vandevska-Radunovic, V.; Grano, M.; Reseland, J.E. Irisin promotes growth, migration and matrix formation in human periodontal ligament cells. Arch. Oral Biol. 2020, 111, 104635. [CrossRef] 
18. Son, J.W.; Choi, S.H.; Jang, J.H.; Koh, J.T.; Oh, W.M.; Hwang, Y.C.; Lee, B.N. Irisin promotes odontogenic differentiation and angiogenic potential in human dental pulp cells. Int. Endod. J. 2020. [CrossRef] [PubMed]

19. Qiao, X.; Nie, Y.; Ma, Y.; Chen, Y.; Cheng, R.; Yin, W.; Hu, Y.; Xu, W.; Xu, L. Irisin promotes osteoblast proliferation and differentiation via activating the MAP kinase signaling pathways. Sci. Rep. 2016, 6, 18732. [CrossRef] [PubMed]

20. Colaianni, G.; Cuscito, C.; Mongelli, T.; Oranger, A.; Mori, G.; Brunetti, G.; Colucci, S.; Cinti, S.; Grano, M. Irisin enhances osteoblast differentiation in vitro. Int. J. Endocrinol. 2014, 2014. [CrossRef]

21. Zeng, R.; Ma, Y.; Qiao, X.; Zhang, J.; Luo, Y.; Li, S.; Liu, L.; Xu, L. The effect of His-tag and point mutation on the activity of irisin on MC3T3-E1 cells. Biosci. Trends 2018, 12, 580-586. [CrossRef]

22. Colaianni, G.; Cuscito, C.; Mongelli, T.; Pignataro, P.; Buccoliero, C.; Liu, P.; Lu, P.; Sartini, L.; Di Comite, M.; Mori, G. The myokine irisin increases cortical bone mass. Proc. Natl. Acad. Sci. USA 2015, 112, 12157-12162. [CrossRef]

23. Luo, Y.; Qiao, X.; Ma, Y.; Deng, H.; Xu, C.C.; Xu, L. Disordered metabolism in mice lacking irisin. Sci. Rep. 2020, 10, 17368. [CrossRef] [PubMed]

24. Luo, Y.; Ma, Y.; Qiao, X.; Zeng, R.; Cheng, R.; Nie, Y.; Li, S.; Shen, X.; Yang, M.; Xu, C.C.; et al. Irisin ameliorates bone loss in ovariectomized mice. Climacteric J. Int. Menopause Soc. 2020, 23, 496-504. [CrossRef] [PubMed]

25. Di Benedetto, A.; Carbone, C.; Mori, G. Dental pulp stem cells isolation and osteogenic differentiation: A good promise for tissue engineering. Methods Mol. Biol. 2014, 117-130. [CrossRef]

26. Ballini, A.; Di Benedetto, A.; De Vito, D.; Scarano, A.; Scacco, S.; Perillo, L.; Posa, F.; Dipalma, G.; Paduano, F.; Contaldo, M.; et al. Stemness genes expression in naive vs. osteodifferentiated human dental-derived stem cells. Eur. Rev. Med. Pharmacol. Sci. 2019, 23, 2916-2923. [CrossRef] [PubMed]

27. Brunetti, G.; Di Benedetto, A.; Posa, F.; Colaianni, G.; Faienza, M.F.; Ballini, A.; Colucci, S.; Passeri, G.; Lo Muzio, L.; Grano, M.; et al. High expression of TRAIL by osteoblastic differentiated dental pulp stem cells affects myeloma cell viability. Oncol. Rep. 2018, 39, 2031-2039. [CrossRef] [PubMed]

28. Kim, H.; Wrann, C.D.; Jedrychowski, M.; Vidoni, S.; Kitase, Y.; Nagano, K.; Zhou, C.; Chou, J.; Parkman, V.-J.A.; Novick, S.J. Irisin mediates effects on bone and fat via $\alpha \mathrm{V}$ integrin receptors. Cell 2018, 175, 1756-1768.e1717. [CrossRef]

29. Chen, Q.; Kinch, M.S.; Lin, T.H.; Burridge, K.; Juliano, R. Integrin-mediated cell adhesion activates mitogen-activated protein kinases. J. Biol. Chem. 1994, 269, 26602-26605. [CrossRef]

30. Hanna, H.; Mir, L.M.; Andre, F.M. In vitro osteoblastic differentiation of mesenchymal stem cells generates cell layers with distinct properties. Stem Cell Res. Ther. 2018, 9, 203. [CrossRef]

31. Perakakis, N.; Triantafyllou, G.A.; Fernández-Real, J.M.; Huh, J.Y.; Park, K.H.; Seufert, J.; Mantzoros, C.S. Physiology and role of irisin in glucose homeostasis. Nat. Rev. Endocrinol. 2017, 13, 324-337. [CrossRef] [PubMed]

32. Zoch, M.L.; Clemens, T.L.; Riddle, R.C. New insights into the biology of osteocalcin. Bone 2016, 82, 42-49. [CrossRef] [PubMed]

33. Price, P.A.; Otsuka, A.; Poser, J.W.; Kristaponis, J.; Raman, N. Characterization of a gamma-carboxyglutamic acid-containing protein from bone. Proc. Natl. Acad. Sci. USA 1976, 73, 1447-1451. [CrossRef]

34. Van de Loo, P.; Soute, B.; Van Haarlem, L.; Vermeer, C. The effect of Gla-containing proteins on the precipitation of insoluble salts. Biochem. Biophys. Res. Commun. 1987, 142, 113-119. [CrossRef]

35. Price, P.A.; Williamson, M.K.; Haba, T.; Dell, R.B.; Jee, W. Excessive mineralization with growth plate closure in rats on chronic warfarin treatment. Proc. Natl. Acad. Sci. USA 1982, 79, 7734-7738. [CrossRef] [PubMed]

36. Ducy, P.; Desbois, C.; Boyce, B.; Pinero, G.; Story, B.; Dunstan, C.; Smith, E.; Bonadio, J.; Goldstein, S.; Gundberg, C. Increased bone formation in osteocalcin-deficient mice. Nature 1996, 382, 448-452. [CrossRef]

37. Colaianni, G.; Faienza, M.F.; Sanesi, L.; Brunetti, G.; Pignataro, P.; Lippo, L.; Bortolotti, S.; Storlino, G.; Piacente, L.; D’Amato, G. Irisin serum levels are positively correlated with bone mineral status in a population of healthy children. Pediatric Res. 2019, 85, 484-488. [CrossRef]

38. Colaianni, G.; Errede, M.; Sanesi, L.; Notarnicola, A.; Celi, M.; Zerlotin, R.; Storlino, G.; Pignataro, P.; Oranger, A.; Pesce, V. Irisin Correlates Positively with BMD in a Cohort of Older Adult Patients and Downregulates the Senescent Marker p21 in Osteoblasts. J. Bone Miner. Res. 2020. [CrossRef]

39. Ritter, N.M.; Farach-Carson, M.C.; Butler, W.T. Evidence for the formation of a complex between osteopontin and osteocalcin. J. Bone Miner. Res. 1992, 7, 877-885. [CrossRef] [PubMed]

40. Hoang, Q.Q.; Sicheri, F.; Howard, A.J.; Yang, D.S. Bone recognition mechanism of porcine osteocalcin from crystal structure. Nature 2003, 425, 977-980. [CrossRef]

41. Hauschka, P.V.; Carr, S.A. Calcium-dependent alpha-helical structure in osteocalcin. Biochemistry 1982, 21, 2538-2547. [CrossRef] [PubMed]

42. Poundarik, A.A.; Diab, T.; Sroga, G.E.; Ural, A.; Boskey, A.L.; Gundberg, C.M.; Vashishth, D. Dilatational band formation in bone. Proc. Natl. Acad. Sci. USA 2012, 109, 19178-19183. [CrossRef] [PubMed]

43. Nikel, O.; Laurencin, D.; McCallum, S.A.; Gundberg, C.M.; Vashishth, D. NMR investigation of the role of osteocalcin and osteopontin at the organic-inorganic interface in bone. Langmuir 2013, 29, 13873-13882. [CrossRef]

44. Berezovska, O.; Yildirim, G.; Budell, W.; Yagerman, S.; Pidhaynyy, B.; Bastien, C.; van der Meulen, M.; Dowd, T. Osteocalcin affects bone mineral and mechanical properties in female mice. Bone 2019, 128, 115031. [CrossRef] [PubMed] 